\title{
Emprego de imageamento passivo na análise da variabilidade espacial da turbidez no espelho d'água do Lago Paranoá, Distrito Federal
}

\section{Use of passive imaging for the analysis of spatial variability of superficial water turbidity at the Lake Paranoá, Federal District, Brazil}

\author{
Edilson de Souza Bias \\ Doutor em Geografia pela Universidade Estadual Paulista "Júlio de Mesquita Filho" (UNESP). Professor do Instituto de Geociências \\ da Universidade de Brasília (IGD/UnB) - Brasília (DF), Brasil.
}

Felipe Lima Ramos Barbosa

Mestre em Geografia Geoprocessamento e Gestão Territorial, Departamento de Geografia (GEA/H), Universidade de Brasília (UnB), Campus Darcy Ribeiro - Brasília (DF), Brasil.

\section{Ricardo Seixas Brites}

Doutor em Engenharia Florestal pela UFV/Colorado Spring. Professor do Instituto de Geociências da Universidade de Brasília (IGD/UnB). Instituto de Geociências (IG/UNB), Universidade de Brasília (UNB), Campus Darcy Ribeiro - Brasília (DF), Brasil.

\section{Resumo}

A água tem importante papel na sociedade humana, especialmente no Brasil. Seus usos são múltiplos, incluindo o abastecimento, produção energética e lazer, entre outros. A própria Política Nacional de Recursos Hídricos (Lei n 9.433/97) traz entre seus artigos a sua importância segundo os seus usos múltiplos, priorizando o abastecimento humano e a dessedentacão de animais. Neste enfoque é importante considerar a qualidade físico-química da água para atender a estas demandas, escopo do enquadramento dos corpos d'água segundo seus usos preponderantes, com o objetivo de garantir qualidade compatível com os usos mais exigentes a que for destinada e diminuir os custos de combate à poluição mediante ações preventivas permanentes. Entre os vários parâmetros que buscam analisar a qualidade físico-química da substância busca-se entender a distribuição espacial da turbidez na superfície do lago, uma vez que a variação dos componentes que alteram este parâmetro pode ser detectada por meio do sensoriamento remoto passivo. A aplicação do Modelo linear de mistura espectral permitiu, de forma satisfatória, identificar a distribuição espacial da turbidez no espelho de água.

Palavras-chave: sensoriamento remoto; modelo linear de mistura espectral; turbidez; sedimentos.

\section{Abstract}

The water has an important role in human society, especially in Brazil. Its uses are multiple, including supply, energy production, recreation and others. The National Policy for Water Resources (Law No 9.433/97) states in its articles the importance of water use in accordance to their multiple uses, prioritizing the supply for humans and animals. In this approach, it is important to consider the physical and chemical quality of water to meet these demands, scope of the legal framework applied to the Brazilian water bodies according to their main uses, in order to guarantee the water quality compatible with the most demanding uses and to reduce the costs of pollution control through ongoing preventive actions. Among the various parameters that seek to analyze the physical and chemical quality of water it is intended to understand the spatial distribution of turbidity in the lake's surface, since the variation of the components that alter this parameter can be detected by means of passive remote sensing. The application of the Linear spectral mixture model allowed, satisfactorily, the identification of turbidity spatial distribution patterns in the lake.

Keywords: remote sensing; linear spectral mixture model; turbidity; sediments.

Endereço para correspondência: Edilson de Souza Bias - Universidade de Brasília - Campus Universitário Darcy Ribeiro - Asa Norte - $70910-900$ - Brasília (DF), 


\section{Introdução}

O Brasil, com todas as suas riquezas minerais e ambientais, possui uma ampla rede hidrográfica que atende aos mais variados usos. No ano 2000 foram retirados $1.592 \mathrm{~m}^{3} . \mathrm{s}^{-1}$ de água dos mananciais para atender a demandas específicas, sendo que $53 \%$ foram efetivamente consumidos e o restante retornou às diversas bacias (BRASIL, 2005). Diante de tal demanda tornam-se inquestionáveis a preservação e o desenvolvimento de políticas públicas capazes de atender a um sistema de real gestão dos recursos hídricos, bem como de suas bacias hidrográficas associadas.

Este sistema de gestão dos recursos hídricos brasileiros foi concebido pela Lei Federal no 9.433/97, conhecida como Lei das Águas. Esta, por sua vez, institui a Política Nacional de Recursos Hídricos e possui como fundamentos, entre outros, o Art 10: "IV A gestão de recursos hídricos deve sempre proporcionar o uso múltiplo das águas".

Atualmente observa-se no Brasil como senso comum que a água é um recurso inesgotável, devido à falsa impressão que as grandes vazões de seus rios causam na população. Ao contrário deste discurso, ela está distribuída de forma irregular no tempo e no espaço, segundo diferentes condições geográficas, climáticas e meteorológicas, justificando a ocorrência aleatória deste recurso finito e renovável (SETTI, 1996). Assim, o levantamento de informações a respeito de sua qualidade é estratégico no suporte ao planejamento da gestão e concessão de outorgas de uso da água, bem como para atender à atual e às futuras gerações no que se refere à necessária disponibilidade de água em padrões de qualidade adequados aos usos pretendidos (Art. $2^{\circ}$, Inciso I, Lei no 9.433/97).

A partir de uma análise sistêmica de bacia hidrografia, a carga de efluentes, orgânicos e inorgânicos, à montante de um reservatório de água urbano, quando carreado pela chuva, interfere nos padrões de qualidade deste ente hídrico, afetando os seus diferentes usos. O aumento da concentração destes materiais altera a luminosidade que penetra na coluna d'água, modificando, consequentemente, o sistema de trocas gasosas.

Baseado nas premissas apresentadas, o objetivo principal do presente artigo é analisar, por meio da técnica do Modelo linear de mistura espectral (MLME), as mudanças sazonais (período seco e período chuvoso) da turbidez da água, do reservatório urbano (Lago Paranoá, DF).

\section{Referêncial teórico}

\section{Sensoriamento remoto e a coloração da água}

Entre muitos métodos de extração de informações associadas a parâmetros de qualidade da água, o sensoriamento remoto abriu uma nova perspectiva nos estudos hídricos por meio da análise da resposta eletromagnética deste recurso natural. Assim, uma significativa quantidade de pesquisas vem sendo desenvolvida para criar métodos que atendam aos levantamentos deste tipo de medida hidrológica, com o intuito de fornecerem medidas espaciais quantitativas da coluna d'água (JENSEN, 2009).

A água líquida em seu estado puro (sem constituintes suspensos ou dissolvidos) possui uma baixa reflectância mesmo na região do visível. Segundo Novo (2008), ela apresenta baixo índice de reflectância, entre 0,38 e 0,7 mm ( $<<0,1)$, absorvendo toda a radiação incidente acima de 0,7 mm. A Figura 1 apresenta a reflectância da água em três diferentes estados.

Lagos oligotróficos (ecossistema pobre em nutrientes) e profundos apresentam resposta típica da água em seu estado puro, uma vez que a luz é atenuada com a profundidade e não se tem o retorno para o observador (sensor remoto). Nestes tipos de ambientes, a água tem coloração escura.

Porém, alguns componentes opticamente ativos afetam a relação padrão que a radiação eletromagnética tem com a coluna d'água, como organismos vivos (fitoplâncton, zooplâncton e bacterioplâncton); partículas em suspensão, orgânicas ou inorgânicas; e substâncias orgânicas dissolvidas (NOVO, 2008).

Segundo Jensen (2009), muitos corpos d'água apresentam de maneira simultânea estes componentes, nas mais variadas concentrações, constituindo-se em um desafio para o sensoriamento remoto derivar informações quantitativas específicas sobre os índices. Basicamente, a existência conjunta de matérias em suspensão e de clorofila na coluna d'água é a responsável pela variação quantitativa na resposta espectral da água.

A variação de concentração de clorofila " $a$ " é responsável pelo aumento da reflectância em quase todos os comprimentos de onda, sendo mais expressiva na região do verde (em virtude do processo de fotossíntese) e do Infravermelho próximo (IVP).

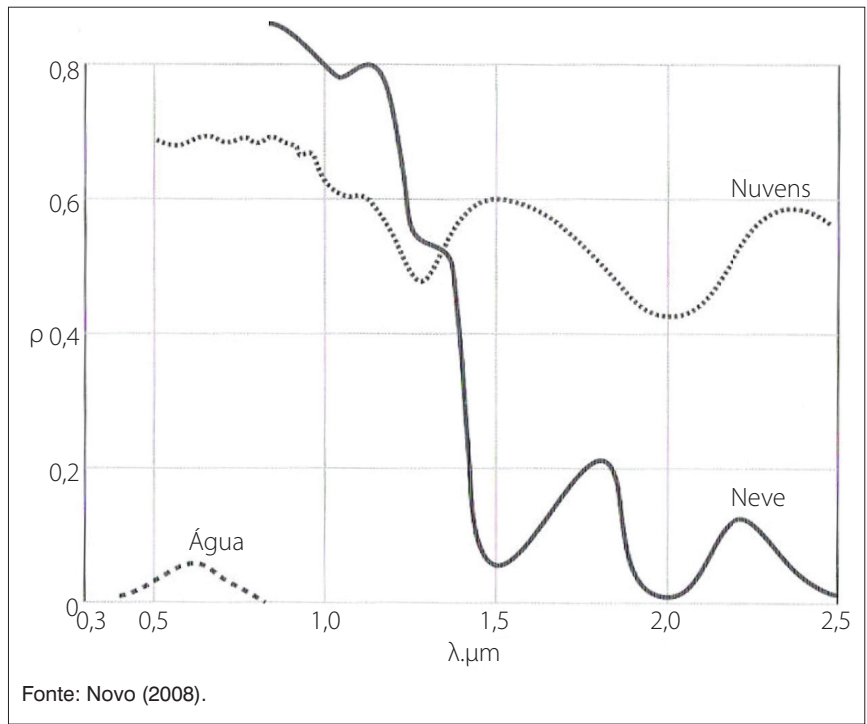

Figura 1 - Comportamento espectral da água no estado líquido, neve e nuvem. 
O aumento expressivo da reflectância na porção do IVP, devido ao acréscimo de clorofila " $a$ ", é explicado quando o espalhamento celular supera o efeito da absorção, tendo, assim, uma resposta semelhante à vegetação, se ocorre floração à superfície deste tipo de componente (NOVO, 2008).

Quanto à matéria orgânica dissolvida, o aumento de concentração deste componente opticamente ativo na coluna d'água causa acentuado grau de absorção na região do azul, possuindo a relação oposta em comprimentos de ondas entre o visível e o IVP. Segundo Mobley (1994) e Novo (2008), esta inversão é explicada em virtude de grandes moléculas dos componentes orgânicos, cujas dimensões seriam equivalentes ao comprimento de onda, favorecendo o espalhamento molecular da energia eletromagnética.

Considerando a influência dos sedimentos em suspensão, os solos argilosos e siltosos, quando presentes na coluna d'água, acarretam o aumento das refletâncias em todos os comprimentos de ondas, principalmente com relação aos picos de refletância na região de 580-690 nm e no IVP. Segundo Jensen (2009), mais fluxo radiante no verde, vermelho e IVP é refletido da coluna d'água e registrado pelo sistema sensor, responsável pela fisionomia mais clara destes cursos de água com relação a um ente hídrico com menores concentrações de sedimentos inorgânicos suspensos.

Vale ressaltar que os solos argilosos, por possuírem mais matéria orgânica, imprimem à coluna d'água uma coloração mais escura, se comparados com os solos siltosos. Esta característica pode ser observada na Figura 2, uma vez que os solos siltosos apresentaram aproximadamente $10 \%$ a mais de reflectância em todos os comprimentos de onda se comparado aos solos argilosos (JENSEN, 2009).

Assim, a atuação conjunta destes componentes nos cursos e massas de água caracteriza sua resposta espectral principalmente na região do visível e do IVP. O fato explica as diferentes aparências visuais (coloração) existentes na natureza.

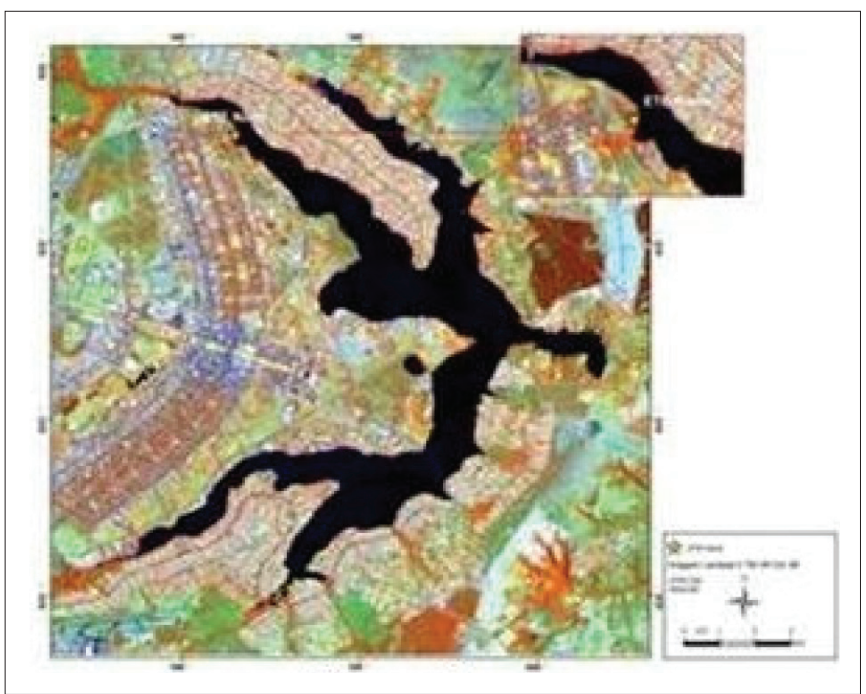

Figura 2 - Cena (4R 5G 3B) Landsat $5 \mathrm{TM}+$ do período seco com a localização da ETE Norte.
Com base nestes parâmetros, Sioli (1990) classificou as águas presentes na natureza em dois grandes grupos, águas pretas ou escuras e águas claras ou brancas. As primeiras consistem, segundo o autor, em corpos hídricos de coloração marrom oliva ao marrom café devido às baixas concentrações de materiais inorgânicos dissolvidos, bem como a presença de substâncias húmicas e fúlvicas dissolvidas. Localizam-se em regiões com pouca ação erosiva, como as águas encontradas na região amazônica (Rio Negro), em área de densa floresta pluvial.

A classe de águas brancas, por outro lado, apresenta concentrações mais elevadas de clorofila a (atividade fitoplanctônica) e de matéria inorgânica dissolvida, a exemplo das existentes nas regiões de cerrado onde se observam épocas marcantes de chuva e seca, carreando uma grande quantidade de matérias orgânica e inorgânica dissolvidas na época chuvosa, e apresentando águas cristalinas nas épocas secas (SILVA, 2008)

A análise conjunta da variação dos componentes opticamente ativos e sua interferência no comportamento espectral da água com a classificação teórica, apresentada por Sioli (1990), das classes água branca e preta, fornecem o embasamento técnico-científico necessário para a discussão do parâmetro de turbidez em massas de água, tais como no estudo de caso do Lago Paranoá.

\section{MLME e sua aplicação na análise da turbidez da coluna d'água}

Com o advento de imagens de sensoriamento remoto orbital foi possível o desenvolvimento de técnicas de extração de informação a partir dos números digitais (ND) de cada banda do sensor. Este tipo de técnica consiste em um processo quantitativo de atribuir um significado único (rótulo) a um determinado conjunto de pixels segundo suas similaridades espectrais e espaciais disponíveis (Novo, 2008). O processo é conhecido como Classificação.

Dentre as muitas técnicas de classificação, o MLME pressupõe que a resposta de um determinado pixel, num determinado sensor, seja a resposta da combinação linear de cada elemento presente no seu interior, consideradas as suas devidas proporções (SHIMABUKURO \& SMITH, 1991; SILVA, 2008). A Equação 1 mostra esta relação matemática da proporção de cada elemento no interior de um determinado pixel.

$r_{i}=\sum\left(a_{i j} \cdot x_{j}\right)+e_{i}$

onde:

$r_{i}=$ reflectância espectral média na banda $i$ de um pixel com um ou mais componentes;

$a_{i j}=$ reflectância espectral conhecida do componente puro $j$ na banda $i$;

$\mathrm{x}_{\mathrm{j}}=$ proporção do componente puro $\mathrm{j}$ dentro do pixel;

$e_{\mathrm{i}}=$ erro de estimativa para a banda $i$;

$j=1,2, \ldots, n=$ número de componentes puros considerados no problema; 
$i=1,2, \ldots, \mathrm{m}=$ número de bandas do sensor;

Desta forma, a referida técnica de classificação estima a contribuição espectral de cada elemento a partir do conhecimento dos membros puros (endmembers) que compõem aquele pixel.

As reflectâncias espectrais para estes membros puros podem ser determinadas in locu e/ou laboratório por meio da utilização de espectrorradiômetros de campo ou por técnicas empírico-quantitativas aplicadas sobre as informações obtidas diretamente dos sensores remotos. Segundo Carvalho Junior et al. (2003), é possível representar os dados espectrais em uma forma geométrica conhecida por Simplex, cujo propósito é estimar o agrupamento dos membros finais de cada classe desejada para a aplicação no MLME.

A disposição espacial das respostas espectrais, de um determinado sensor, em um espaço n-dimensional de atributos, apresenta-se, num primeiro momento, sem correlação de seus eixos e dimensionalidades. Após a aplicação de procedimentos como o Análise de Principais Componentes (ACP) ou Minimum Noise Fraction (MNF) são geradas figuras geométricas simplex que descrevem os membros finais, bem como os componentes de sua mistura, com base nas amostras desejadas (SMITH; JOHNSON; ADAMS, 1985). Nesta etapa, é possível observar o comportamento em "nuvem" dos elementos puros, uma vez que esta é uma solução ótima para análises de cunho linear. A Figura 3 mostra um espaço n-dimensional após a aplicação do procedimento de MNF (redução espectral) sobre dados do sensor Landsat 5 TM+, seguido da aplicação de um procedimento de redução espacial dos dados, a partir do Índice de Pureza do Pixel — Pixel Purity Index (PPI).

O procedimento de redução espacial da dimensionalidade dos dados (PPI) é baseia-se na redução espacial dos dados pré-processados no MNF, com o intuito de auxiliar o intérprete

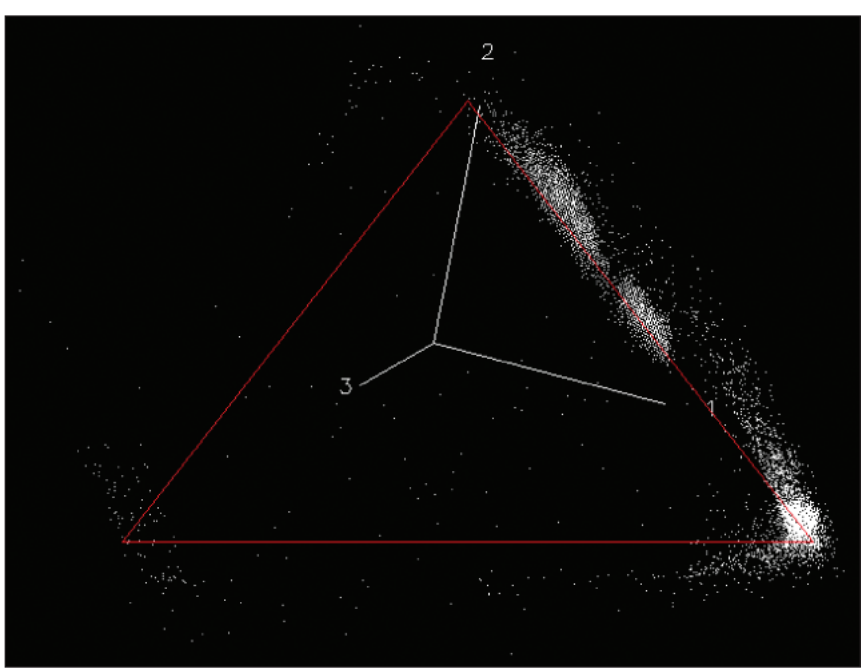

Figura 3 - Espaço n-dimensional após a aplicação do procedimento de Minimum Noise Fraction, seguido do Pixel Purity Index. 0 triângulo vermelho representa uma concepção da geometria simplex. na definição dos membros puros de interesse. Segundo Smith, Johnson e Adams (1985), esta metodologia está em harmonia com o método de MLME. Assim, o PPI consiste em n-reprojeções da forma geométrica simplex dentro da dimensionalidade espacial do dado, contabilizando e registrando a pureza de cada elemento (CARVALHO JÚNIOR et al., 2003). Esta informação pode ser observada na Figura 3.

Portanto, a partir dos passos teóricos desenvolvidos pelo simplex é possível estimar os membros finais desejados. No presente caso serão analisadas as classes de água preta e branca.

\section{Metodologia de trabalho}

Para o desenvolvimento desta pesquisa, foram utilizadas as cenas de dois períodos diferentes da plataforma Landsat 5 sensor TM, um compreendendo a época chuvosa (11 de outubro de 2005), característica do final do ano na região do Distrito Federal, e outra da época seca (23 de julho de 2005). A escolha delas se deu pela dificuldade de imageamento em épocas de chuva, com grande cobertura de nuvens.

Com a utilização da série histórica de pluviosidade da Estação de Tratamento de Esgoto (ETE) Norte, foi possível selecionar o único momento disponível condizente com os objetivos de pesquisa. A cena de 11 de outubro de 2005 é posterior a um intervalo de 25 dias de chuva, sem presença expressiva de nuvens. A Figura 4 apresenta a cena correspondente ao período chuvoso, bem como a localização da ETE Norte.

Já a cena de 23 de julho de 2005 corresponde ao período seco (Figura 2) e foi selecionada uma vez que pertence ao mesmo ano, condizente com a proposta da pesquisa.

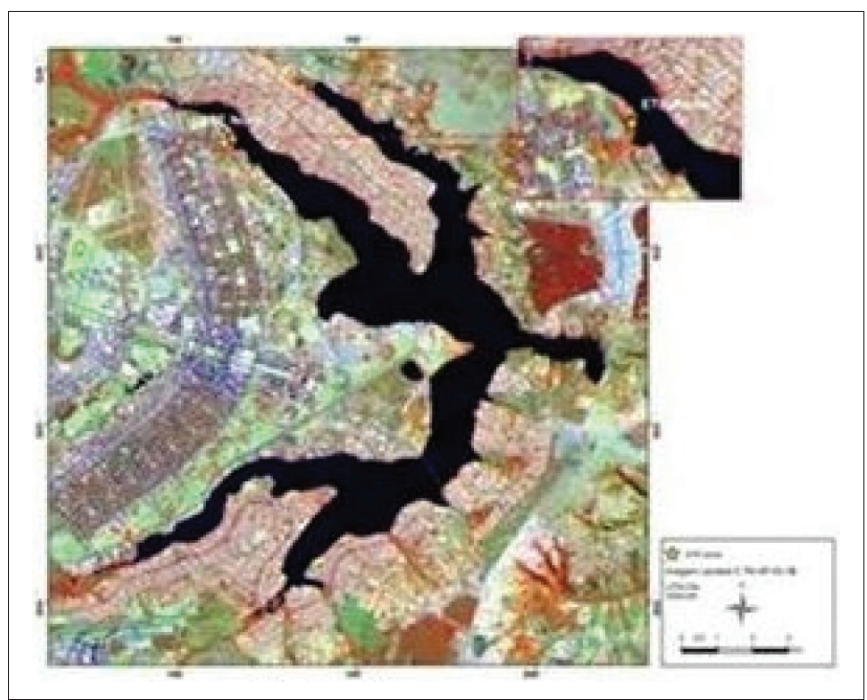

Figura 4 - Cena (4R 5G 3B) Landsat 5 TM+ do período chuvoso com a localização da ETE Norte . 
De posse dos dados das respectivas épocas chuvosa e seca, foram implementados os procedimentos definidos no fluxograma que consta na Figura 5.

O primeiro passo foi o pré-processamento das cenas Landsat 5 TM visando realizar a correção geométrica e radiométrica do dado. Utilizaram-se os valores de "ganho" e "offset" padrão para os imageamentos deste sensor, bem como a data de aquisição da imagem e o ângulo zenital solar determinado. O intuito desta etapa foi a transformação dos números digitais (NDs) para dados de reflectância aparente.

A seguir efetuou-se a identificação e extração dos membros finais (endmembers), por meio de técnicas empírico-quantitativas (Simplex), utilizando o MLME nas bandas 3 (vermelho), 4 (IVP) e 5 (Infravermelho Intermediário). Segundo Jensen (2009), os usos das bandas do IVP e infravermelho de ondas curtas são os melhores para discriminar o limite terra-água, uma vez que a coluna d'água, quanto mais profunda e "pura" (sem sedimentos suspensos), tende a absorver praticamente todo o fluxo radiante incidente. E de maneira oposta, as coberturas da terra (tipicamente vegetação e solo exposto) refletem quantidades significativas de energia incidente nestes intervalos do espectro.

Assim, para a aplicação do MLME foram utilizadas as bandas 3, 4 e 5 para favorecer a extração dos membros finais das classes selecionadas de vegetação, água e sombra. Com estas informações, geraram-se imagens-fração de cada classe, utilizando o algoritmo de classificação espectral angular (SAM), que segundo Novo (2008) consiste em um algoritmo, desenvolvido especificamente para sistemas hiperespectrais, cujo método de análise dos vetores de um pixel no espaço n-dimensional de atributos é determinar o grau de similaridade entre curvas espectrais dos vários pixels. Uma característica deste algoritmo é que ele está associado apenas à similaridade de forma entre os espectros analisados, não sendo sensível a mudanças abruptas com relação à amplitude destes dados (NOVO, 2008; BARBOSA, 2005).

As imagens-fração são resultantes da aplicação de determinados algoritmos, implementados em diversos softwares de geoprocessamento, que possuem a principal função de transformar a informação espectral de um determinado pixel em valores de informação física em valores de proporcionalidade de determinado endmember naquela célula da imagem (SILVA, 2008). A utilização destes algoritmos condizem com etapas de pós-seleção dos endmembers em metodologias de implementação prática do MLME, já que busca informar a proporcionalidade de dado membro final em cada pixel da imagem. Desta forma, foram elaboradas, na primeira aplicação do MLME, as imagens-fração de vegetação, solo e sombra para os dois períodos de análise, conforme mostrado na Figura 6.

Após a criação das imagens-fração foi possível definir uma máscara binária terra/água, necessária para os passos subsequentes da análise. Uma etapa de correção vetorial foi implementada a este produto no intuito de corrigir inconsistências pontuais ocorridas nas fases de processamento. A máscara binária terra/água, originalmente em formato matricial, foi convertida para formato vetorial, no qual se seguiram ajustes nos vértices do polígono resultante dos corpos hídricos, bem como a

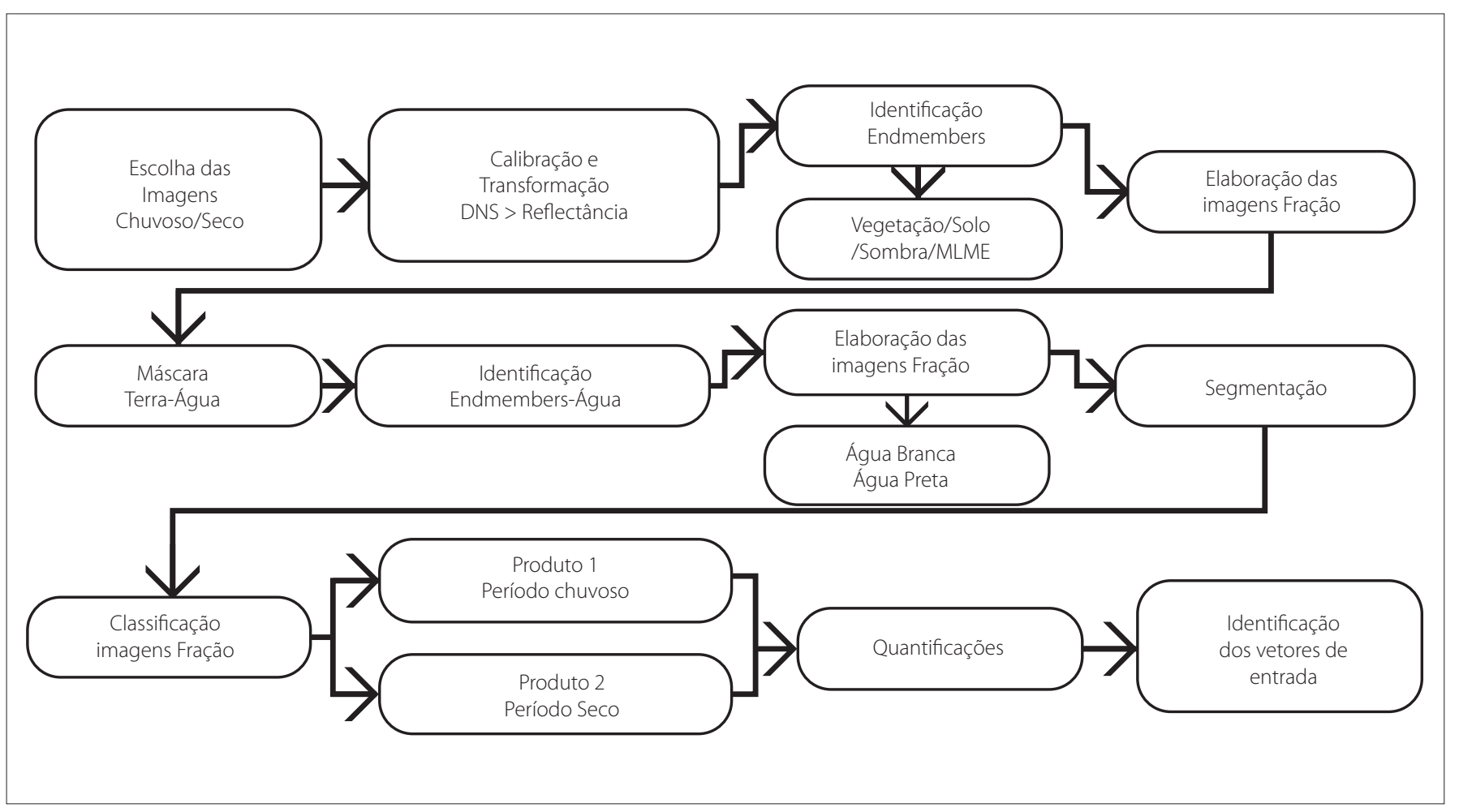

Figura 5 - Fluxograma de procedimentos. 

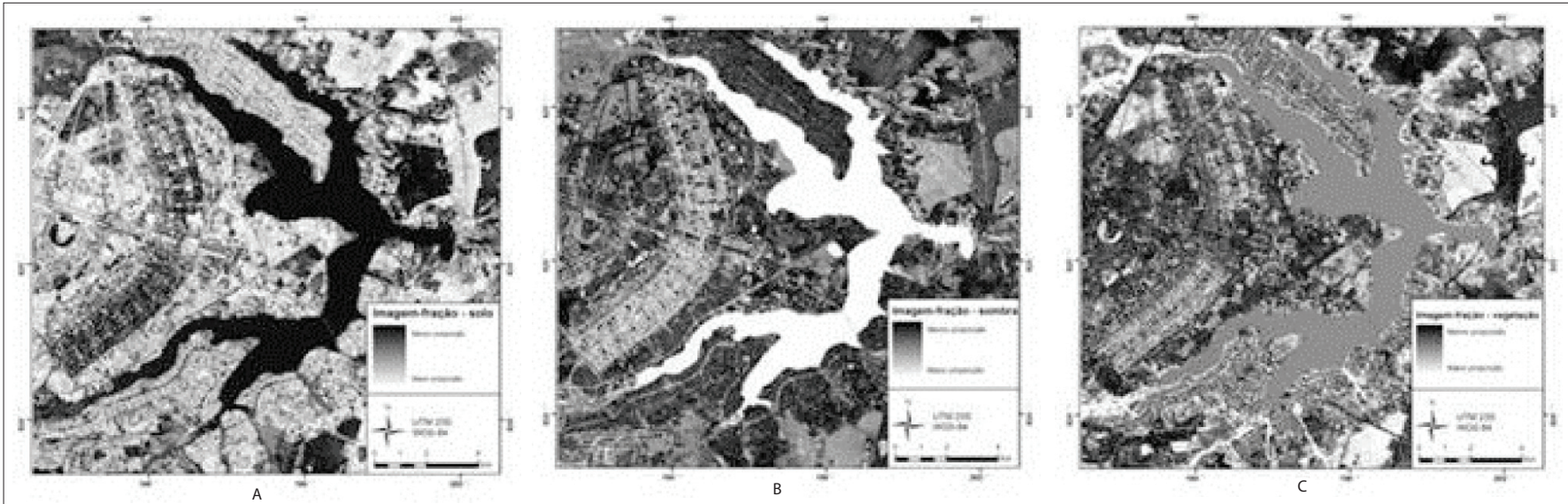

Figura 6 - (A) Imagens-fração dos membros finais: solo; (B) Imagens-fração dos membros finais: sombra; (C) Imagens-fração dos membros finais: vegetação.

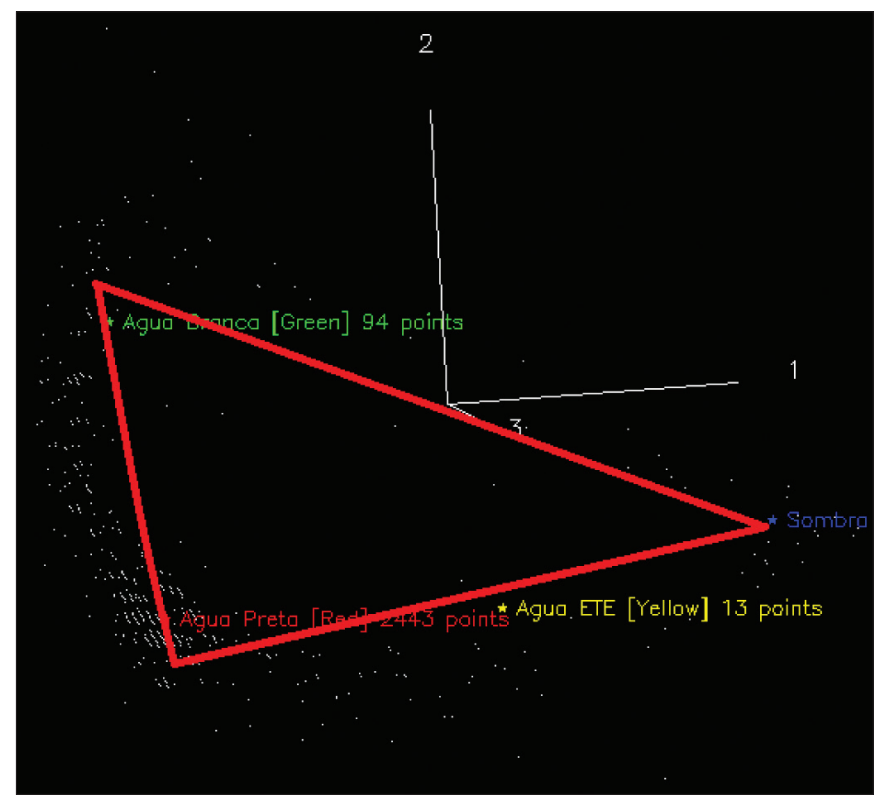

Figura 7 - Espaço n-dimensional com os membros finais "água branca”, "água preta" e sombra.

eliminação de "resíduos" associados à sombra de nuvens. Após as correções, esta informação geográfica foi novamente convertida para formato matricial, atendendo ao padrão de dados utilizados na metodologia.

Com a redução da dimensionalidade dos dados, foi feita uma segunda aplicação do MLME apenas na região de interesse delimitada pela etapa anterior como água, utilizando-se as bandas 1, 2, 3 e 4 . O intuito de usar, nesta etapa, apenas as bandas com informações espectrais da região do visível e IVP é justificado pela sensibilidade do comportamento espectral da coluna d'água à variação na concentração de componentes opticamente ativos, de interesse da presente pesquisa. Na Figura 7 se observa o espaço n-dimensional de atributos com a delimitação do maior número de endmembers que foi possível identificar para atender às classes água branca e preta.
Segundo Novo (2008), este técnica de selecionar o maior número de classes na etapa de pré-classificação é explicada uma vez que quase todos os algoritmos de classificação funcionam a partir de uma distribuição gaussiana ou normal, evitando, assim, ao máximo, amostras bimodais. Vale ressaltar que na segunda etapa de aplicação do MLME foram observados os mesmos procedimentos da primeira, seguido da utilização do classificador angular SAM.

O procedimento permitiu gerar as imagens-fração para a classe água branca e água preta nas duas cenas trabalhadas (chuvosa e seca). Uma vantagem da utilização delas nas análises e aplicações do MLME é a preparação do dado para pós-classificações e extração de informações temáticas, usando algoritmos de segmentação e classificadores por região (SILVA, 2008).

Nestas últimas fases, as quatro imagens-fração geradas foram segmentadas, com o uso do aplicativo Spring, por meio do algoritmo de segmentação por crescimento de região, que se fundamenta na delimitação de segmentos (agrupamentos de pixels contíguos) segundo o parâmetro do limiar de similaridade, baseado no valor de diferença mínima entre dois pixels ou um pixel e a média de um segmento já existente para que sejam alocados a segmentos distintos, e o valor mínimo de área, ou seja, o tamanho mínimo que os segmentos podem ter na análise em questão. Para tanto foram utilizados 8 para limiar de similaridade e 40 para área mínima, estimados de maneira empírica sobre as imagens-fração resultantes. A Figura 8 mostra um exemplo da aplicação deste algoritmo sobre uma das imagens-fração.

A última etapa do método foi a utilização das imagens-fração segmentadas como dado de entrada em um classificador por regiões, no caso o Isoseg (BINS et al., 1996). Este algoritmo de classificação usa a matriz de covariância e o vetor médio das classes para estimar o centro delas num processo de partição inicial dos dados, sendo definido pelo analista um valor de distância mínima — conhecida como distância de Mahalanobis - que servirá de critério para o agrupamento de classes semelhantes. Vale destacar que a 
alocação de um determinado segmento a outro ocasiona todo um rearranjo (recálculo) da matriz de covariância e do vetor média da classe (RICHARDS, 1993).

Após a etapa de aplicação do classificador Isoseg foram obtidos dois produtos. O primeiro associado à cena do período de chuva, com informações da distribuição proporcional das águas branca e preta, e o segundo associado ao período de seca, também com informações da distribuição proporcional de ambas as águas.

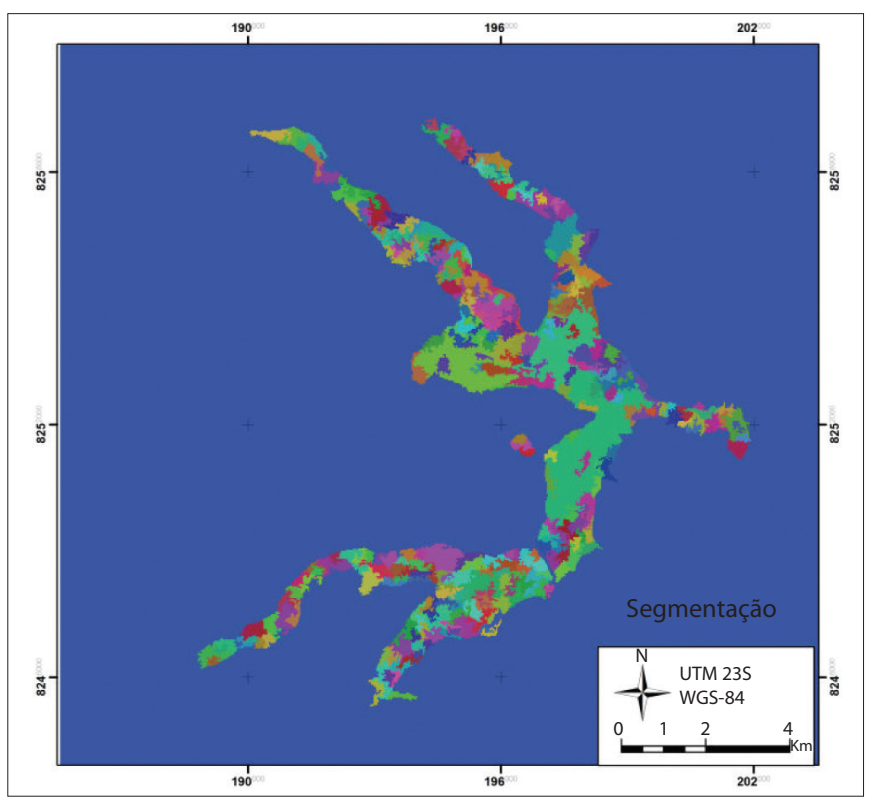

Figura 8 - Resultado da segmentação, por crescimento de região, da imagem-fração "água branca" no período de chuva.

\section{Resultados e discussão}

Com a metodologia, foi possível obter informações associadas à turbidez do Lago Paranoá, localizado em Brasília (DF), em duas épocas climáticas distintas: período chuvoso e período seco. A tentativa de discriminação destes dois momentos e a variação espacial da influência da concentração de sedimentos suspensos, orgânicos e inorgânicos, e de clorofila no espelho de água podem ser observadas nas Figuras 9A e B, com a apresentação das classes água preta para os períodos chuvoso e o seco.

A análise visual das Figuras 9A e B permite perceber que o aumento da carga pluviométrica (período chuvoso) no contexto ambiental avaliado diversifica a ocorrência da classe água preta (Figura 9B) devido à participação dos efluentes lançados a montante nos cursos de água que contribuem com esse reservatório. A Figura 10 traz a relação quantitativa entre a redução das áreas com maior ocorrência de água preta com o aumento da carga pluviométrica sobre o sistema.

As áreas com alta ocorrência de água preta aumentam de 10 para $45 \%$ da área analisada, considerando a transação do período chuva para seca. Estas áreas estão associadas a locais nos quais há distanciamento considerável das margens, tais como a região central do reservatório.

A explicação deste fenômeno é baseada na diminuição da carga de sedimentos dos cursos a montante, bem como do próprio escoamento superficial às margens do reservatório, entre o período chuvoso e o seco, o que nos mostra variação considerável na turbidez do espelho de água.

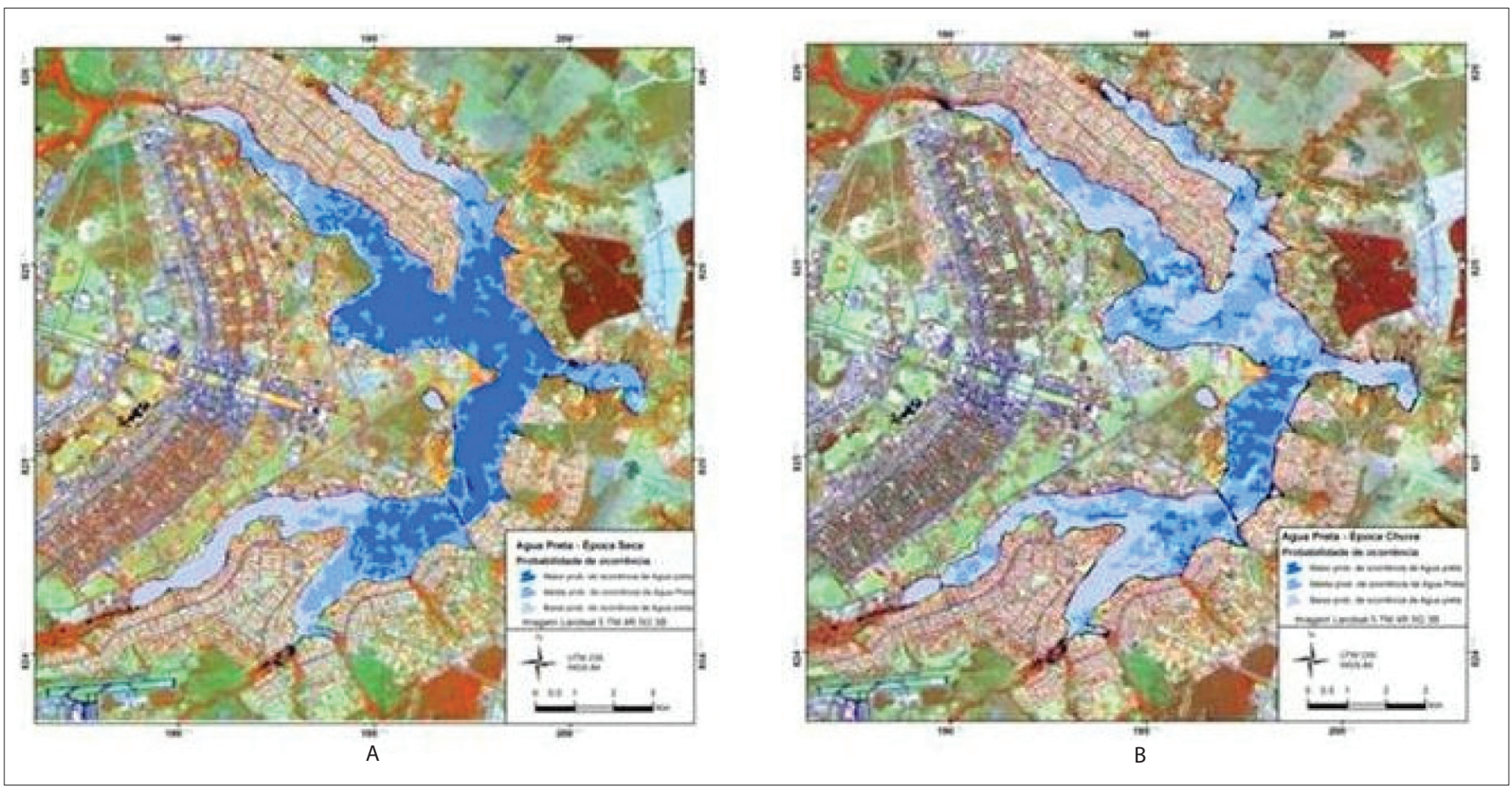

Figura 9 - (A) Produtos para a classe "água preta” no período seco; (B) Produtos para a classe "água preta” no período chuvoso. 
Os produtos encontrados para a classe de água branca reforçam esta análise, numa lógica inversa. As Figuras 11A e B apresentam as classes de água branca nos dois períodos analisados.

No período chuvoso (Figura 11B) observa-se ampla incidência da classe de alta ocorrência de água branca nas vertentes que abastecem o reservatório, principalmente no que corresponde ao Córrego Riacho Fundo (Sudoeste do lago). Isso pode ser explicado pelo elevado grau de urbanização desta bacia hidrografia, no contexto do Distrito Federal.

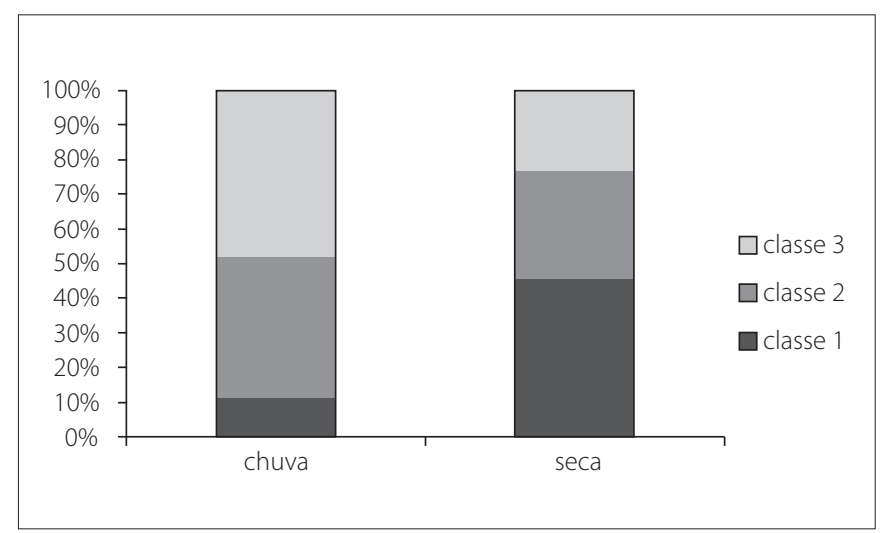

Figura 10-Quantitativo das classes "água preta" nos dois períodos analisados. A classe 1 corresponde às áreas com alta ocorrência de "água"preta"; a classe 2 às áreas com média ocorrência e a classe 3 às com baixa ocorrência.
Durante o período chuvoso, uma elevada concentração de material em suspensão e clorofila é transportada para as águas do reservatório, o que justifica a incidência verificada na classificação subsequente. Este fenômeno é agravado pela contribuição do escoamento superficial das vertentes do reservatório (áreas de média ocorrência próximas às margens do lago). Para exemplificar, a contribuição de sedimentos provindos do bairro residencial Lago Norte (península ao Norte do lago) altera substancialmente a resposta encontrada no corpo hídrico localizado ao final da respectiva área em questão.

Outro ponto interessante consiste na resposta das classes de média e alta ocorrência encontradas no período seco. Por um lado, observa-se que cursos d'água a montante ainda continuam contribuindo com sedimentos, principalmente o mencionado Córrego do Riacho Fundo. Por outro, percebe-se a presença das classes de média e alta ocorrência ao longo da margem Oeste do reservatório, basicamente devido à contribuição de sedimentos provindos de clubes e áreas de lazer. A Figura 12 apresenta a relação quantitativa do aumento das classes de alta ocorrência da classe água branca com o acréscimo da influência pluviométrica.

Com base na Figura 12, nota-se redução acentuada nas áreas de alta e média ocorrência da classe água branca, na transição entre o período chuvoso e o seco. A existência de áreas remanescentes de alta e média ocorrência no período seco está associada à continuada

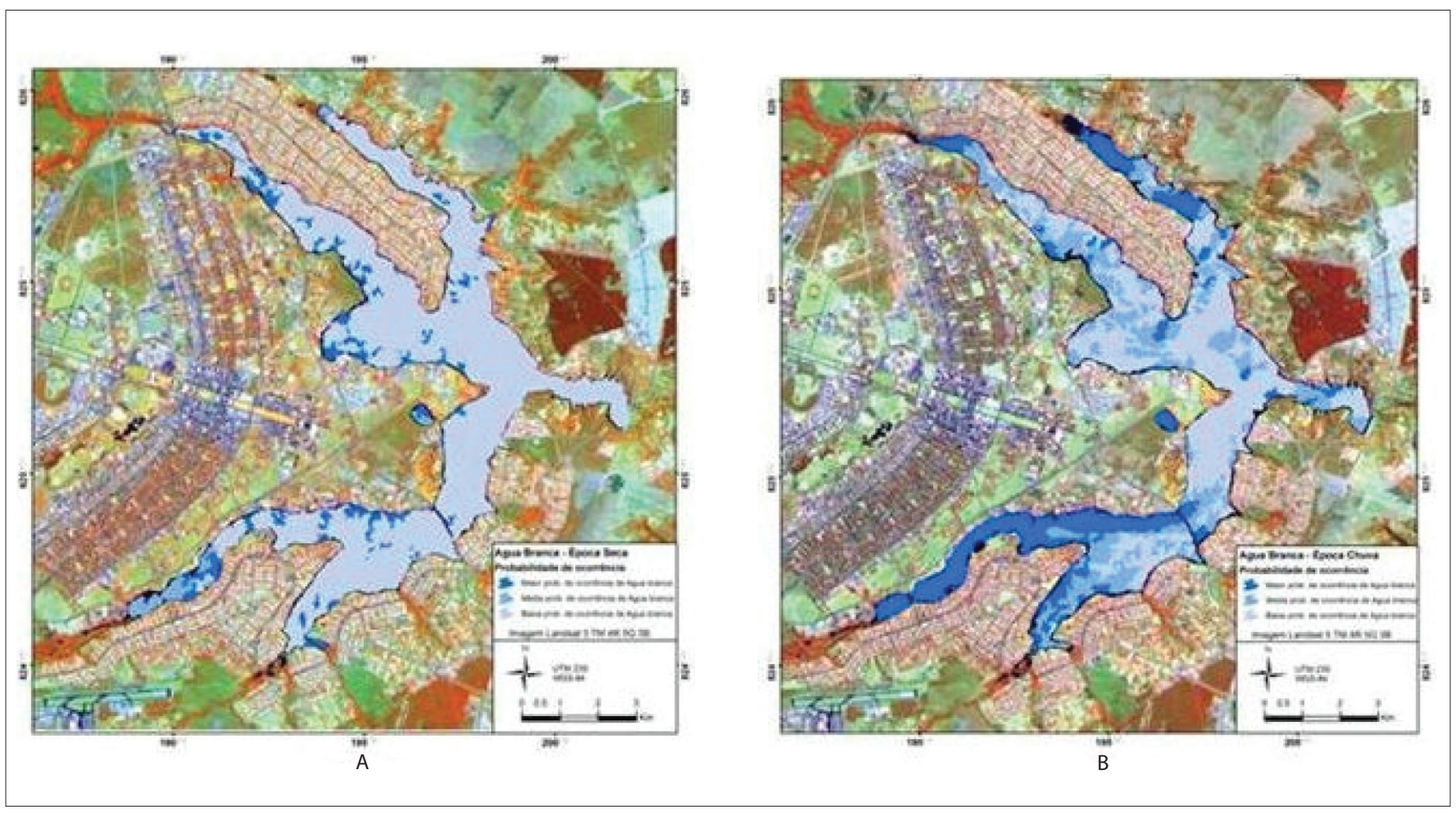

Figura 11 - (A) Produtos para a classe "água branca" no período seco; (B) Produtos para a classe "água branca" no período chuvoso. 


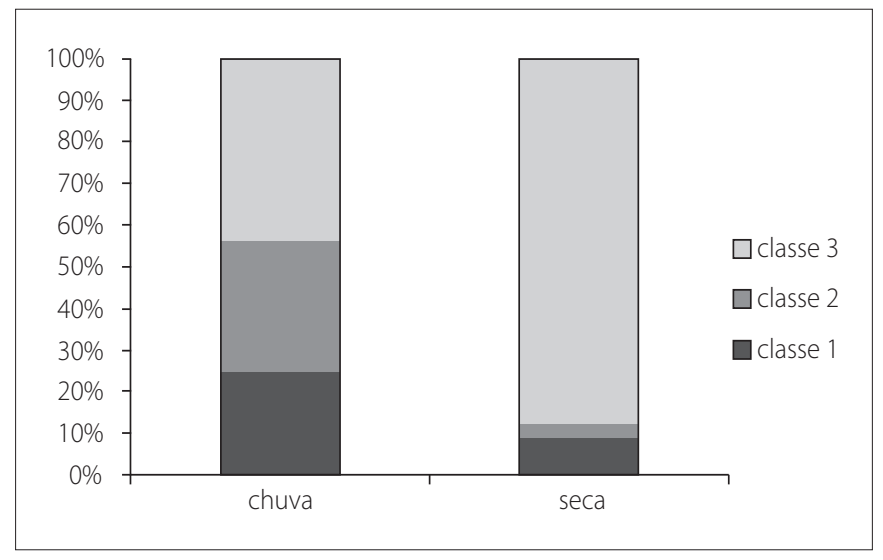

Figura 12 - Quantitativo das classes "água branca" nos dois períodos analisados. A classe 1 corresponde às áreas com alta ocorrência de "água branca"; a classe 2 às áreas com média ocorrência e a classe 3 às com baixa ocorrência.

contribuição dos córregos a montante do reservatório, aquela proveniente das áreas de lazer encontradas ao longo da margem Oeste.

Estes cenários verificados na presente pesquisa trazem à tona uma nova avaliação da proposta de utilização da água do Reservatório do Lago Paranoá para o abastecimento humano. A heterogeneidade observada nas classes de água preta e branca, entre o período chuvoso e seco, mostra que a situação do índice físico de turbidez deve ser considerado nas decisões relativas à utilização da água para este fim.

Depreende-se dos resultados das análises realizadas que o local mais apropriado, segundo o parâmetro da turbidez, para a coleta da água, localiza-se na região central do reservatório, contrariamente ao que vem sendo debatido e proposto pela Companhia de Saneamento Ambiental do Distrito Federal, ou seja, a área próxima à barragem, na extremidade Leste do reservatório.
Os resultados mostraram que durante os períodos de chuva existe uma entrada acentuada de sedimentos no reservatório, o que aumentaria os custos referentes ao tratamento numa futura Estação de Tratamento de Água (ETA), no caso de se adotar a localização que vem sendo proposta.

\section{Considerações finais}

Com o apoio de técnicas e métodos de sensoriamento remoto baseados em imageamento passivo, foi possível estimar a heterogeneidade da água do reservatório nos dois períodos propostos.

Observa-se acentuada contribuição do córrego do Riacho Fundo na distribuição espacial de turbidez no espelho de água, dado o alto grau de antropização dessa unidade hidrográfica.

Os resultados obtidos reforçam a complexidade de estudos envolvendo a qualidade de água, com o uso de sensoriamento remoto. Estes cenários, encontrados na presente pesquisa, trazem à tona uma nova avaliação da proposta de utilização da água do Reservatório do Lago Paranoá para o abastecimento humano. A heterogeneidade observada nas classes de água preta e branca, entre o período chuvoso e seco, mostra que a situação do índice físico de turbidez deve ser considerada nas decisões relativas à utilização desta água para o abastecimento.

É oportuno considerar que os estudos foram realizados somente para a turbidez da coluna superficial d'água, sendo necessárias análises mais detalhadas para a determinação de outros parâmetros físico-químicos e biológicos que podem afetar a qualidade da água do reservatório em função de interesses futuros, principalmente pela influência das contribuições a montante.

Outro aspecto observado foi a relação entre a proximidade das margens e a coloração da água. Percebe-se que o resultado esperado de um padrão com menores índices de turbidez perto da barragem (extremo Leste) não foi verificado devido, basicamente, à contribuição do escoamento superficial das vertentes.

\section{Referências}

BARBOSA, C.C.F. (2005) Sensoriamento remoto da dinâmica de circulação da água do sistema planície de Curai/Rio Amazonas. Tese (Doutorado). São José dos Campos: Instituto de Pesquisas Espaciais. 286 p.

BINS, L.S.; FONSECA, L.M.G.; ERTHAL, G.J.; MITSUO II, F. (1996) Satellite imagery segmentation: a region growing approach. In: Simpósio Brasileiro de Sensoriamento Remoto, 8, Anais... São José dos Campos: INPE, p. 677-680. CD-ROM.

BRASIL. (2005) Ministério do Meio Ambiente. Agência Nacional de Águas. Caderno de recursos hídricos: Disponibilidade e demandas de recursos hídricos no Brasil. Brasília: ANA. 123 p.
CARVALHO JÚNIOR, O.A.; CARVALHO, A.P.F.; GUIMARÃES, R.F.; MENESES, P.R.; SHIMABUKURO, Y.E. (2003) Mistura espectral: (I) detecção dos membros finais utilizando a geometria do simplex. Revista Espaço \& Geografia, v. 6, n. 1, p. 143-73.

JENSEN, J.R. (2009) Sensoriamento remoto do ambiente: uma perspectiva em recursos terrestres. São Jose dos Campos: Parênteses. 604 p.

MOBLEY. C.D. (1994) Light and water: radioactive transfer in natural waters. San Diego: Academic Press.

NOVO, E.M.L.M. (2008) Sensoriamento remoto: princípios e aplicações. 3 ed. São Paulo: Edgard Blucher. 363 p. 
RICHARDS, J.A. \& JIA, X. (1993) Remote sensing digital image analysis: an introduction. 2 ed. Berlim: Springer-Verlag. 340 p.

SETTI, A.A. (1996) A necessidade do uso sustentável dos recursos hídricos. Brasília: IBAMA. 344 p.

SHIMABUKURO, Y.E. \& SMITH, J.A. (1991) The least-squares mixing models to generate fraction images derived from remote sensing multiespectral data. IEEE Transactions on Geocience and Remote Sensing, v. 29, n. 1, p. 16-20.

SILVA, W.C.S. (2008) Aplicação da técnica de Modelo Linear de Mistura Espectral (MLME) para o mapeamento de diferentes tipos de água no rio Solimões e no lago de Coari utilizando imagens Landsat-5 TM. 2008 Dissertação (Mestrado). Rio de Janeiro: Universidade Federal do Rio de Janeiro. $109 \mathrm{p}$.

SIOLI, H. (1990) Amazônia: fundamentos da ecologia da maior região de florestas tropicais. Instituto Max-Planck de limnologia. Petrópolis: Vozes. $92 \mathrm{p}$.

SMITH, M.O.; JOHNSON, P.E.; ADAMS, J.B. (1985) Quantitative determination of mineral types and abundances from reflectance spectra using principal components analysis. Journal of Geophysical Research Solid Earth, v. 90, S.02, p. 797-804. 